\title{
Surgical hepaticogastrostomy as a method for resolving stent migration in endoscopic ultrasound-guided hepaticogastrostomy
}

A 54-year-old woman presented with a 1-month history of jaundice. Abdominal CT showed a perihilar hypodense mass measuring $21 \times 16 \mathrm{~mm}$ in diameter with dilated bilateral intrahepatic bile duct (IHD). Hilar cholangiocarcinoma was diagnosed and palliative biliary drainage was scheduled. Endoscopic ultrasound (EUS)-guided hepaticogastrostomy (EUS-HGS) was performed with the patient under general anesthesia. A linear echoendoscope along with a 19-gauge EUS-FNA needle, a 0.025-inch guidewire, a 6-French cystotome, and serial bougie dilators up to 8.5 French were used. A 120-mm partially covered stent with distal flared end (Giobore biliary stent; Taewoong Medical Co., Ilsan, Korea) was used to bridge the left IHD and stomach using the extra-scope channel deployment technique. The proximal end was successfully placed into the left IHD, but the distal end unfortunately displaced into the peritoneal cavity. We immediately converted EUS-HGS to exploratory laparotomy ( Video 1 ). The displaced distal end of the HGS stent and a hole on the serosal side of the stomach were identified ( $\triangleright$ Fig. 1 ). The distal end of the HGS stent was placed back into the stomach ( $\mathbf{F i g . 2}$ ) and sutured to the stomach wall. Surgical hepaticogastrostomy was then successfully performed with the HGS stent. No postoperative adverse events occurred. The patient resumed a regular diet on day 4 and was discharged on day 7. She has been well without a need for biliary reintervention during 15 months of follow-up.

Stent migration, either as an early event during stent deployment [1] or as late migration due to stent shortening, occurs in about $2 \%$ to $3 \%$ of cases [2]. Migration can be a fatal complication of EUS-HGS.

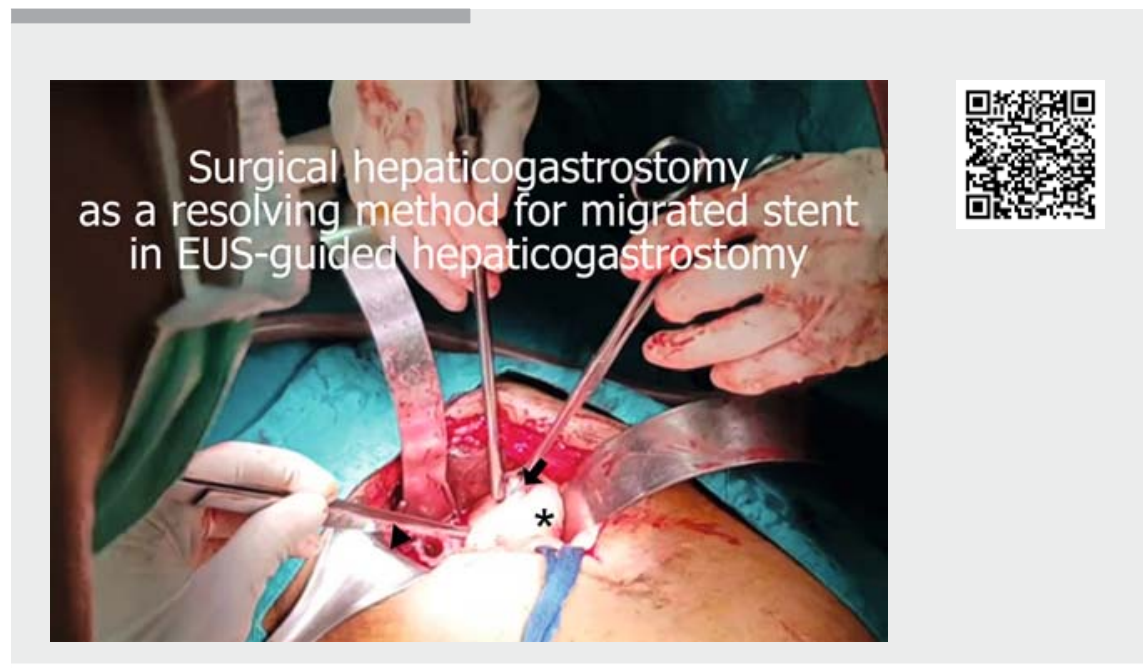

Video 1 Exploratory laparotomy with surgical resolution of migrated stent during endoscopic ultrasound-guided hepatogastrostomy.

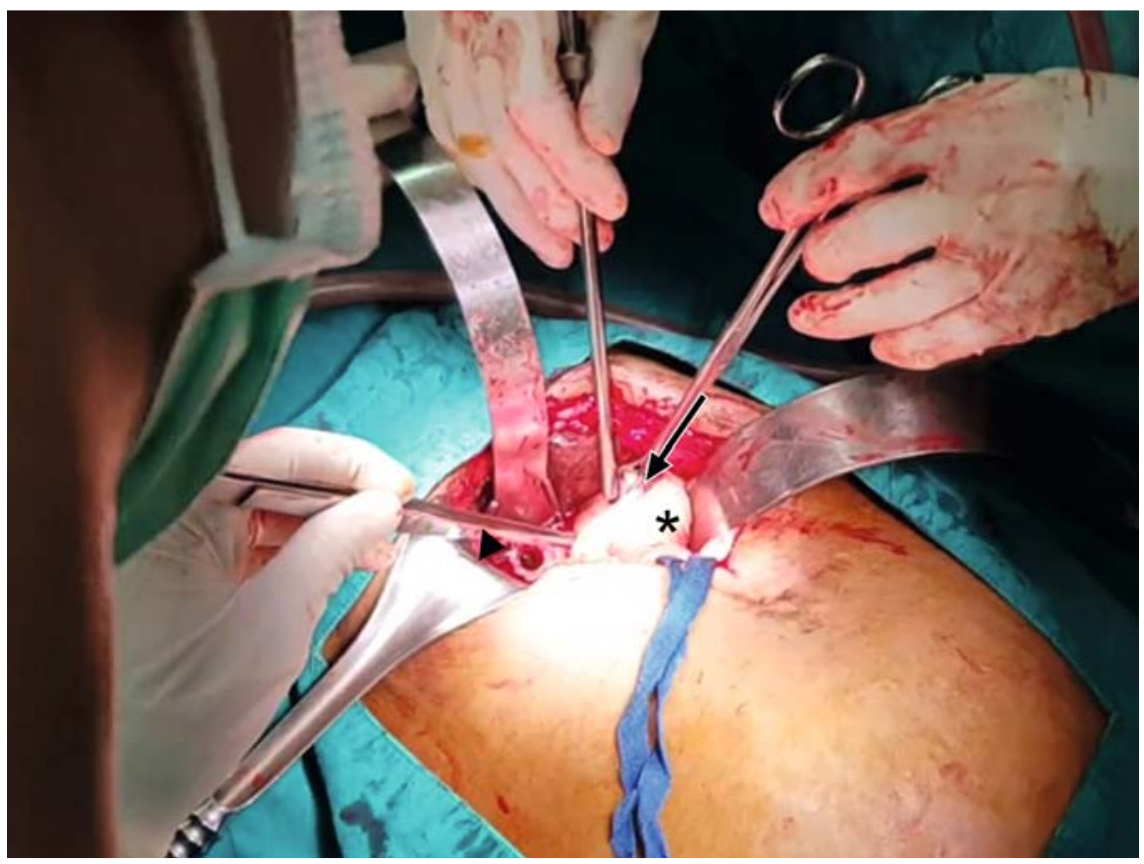

- Fig. 1 During exploratory laparotomy following early stent migration during endoscopic ultrasound-guided hepatogastrostomy, the hepatogastrostomy stent (arrowhead) and the hole (arrow) in the stomach (star) were identified. 


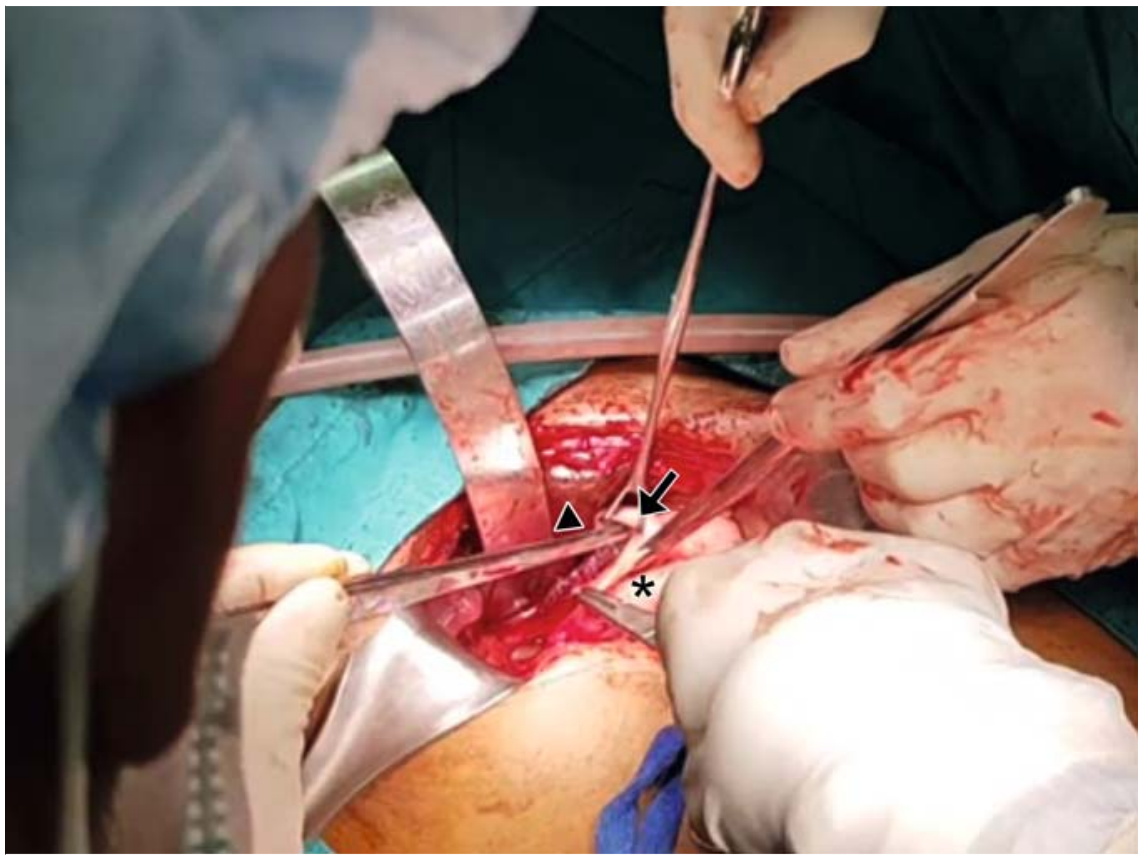

- Fig. 2 During exploratory laparotomy, the hepatogastrostomy stent (arrowhead) was placed back into the hole (arrow) in the stomach (star).

Immediate stent migration can be treated with various techniques such as tandem stent placement [3], surgical removal [4], or endoscopic retrieval [5]. With the present case, we report surgical hepaticogastrostomy as another technique to resolve early HGS stent migration.

Endoscopy_UCTN_Code_CPL_1AL_2AD

\section{Acknowledgements}

Funding information: Pancreas Research Unit, Faculty of Medicine, Chulalongkorn University, Health Systems Research Institute (HSRI), grant number HSRI 62-050

\section{Competing interests}

The authors declare that they have no conflict of interest.

1 Department of Surgery, Roi-Et Hospital, Center and Division of Gastroenterology,
The authors

\section{Passakorn Sodarat ${ }^{1}$, Thanawat}

Luangsukrerk2,3, Pradermchai Kongkam 2,3,

Orathai Seabmuangsai ${ }^{1}$, Chatchawan

Wachiramatharuch ${ }^{1}$ Ministry of Public Health, Thailand

2 Gastrointestinal Endoscopy Excellence Department of Medicine, Faculty of Medicine, Chulalongkorn University and King Chulalongkorn Memorial Hospital, Thai Red Cross Society, Bangkok, Thailand

3 Pancreas Research Unit, Department of Medicine, Faculty of Medicine, Chulalongkorn University, Bankgkok, Thailand

\section{Corresponding author}

\section{Pradermchai Kongkam, MD}

Gastrointestinal Endoscopy Excellence Center, Pancreas Research Unit, Department of Medicine, Chulalongkorn University and King Chulalongkorn Memorial Hospital, Thai Red Cross Society, 1873 Rama 4 Road, Pathumwan, Bangkok, Thailand 10330 Fax: +66-2-652-4219

kongkam@hotmail.com

\section{References}

[1] Ogura T, Yamamoto K, Sano T et al. Stent length is impact factor associated with stent patency in endoscopic ultrasound-guided hepaticogastrostomy. J Gastroenterol Hepatol 2015; 30: 1748-1752

[2] Wang K, Zhu J, Xing L et al. Assessment of efficacy and safety of EUS-guided biliary drainage: a systematic review. Gastrointest Endosc 2016; 83: 1218-1227

[3] Hamada T, Nakai Y, Isayama $\mathrm{H}$ et al. Tandem stent placement as a rescue for stent misplacement in endoscopic ultrasonographyguided hepaticogastrostomy. Dig Endosc 2013; 25: 340-341

[4] So H, Lee JH, Noh JH et al. Surgical removal of a hepaticogastrostomy stent because of its recurrent dislocation into the esophagus. Endoscopy 2020; 52: E148-E149

[5] Fujisawa T, Saito H, Isayama H. Endoscopic removal of a metal stent that migrated into the peritoneal cavity after endoscopic ultrasound-guided hepaticogastrostomy. Dig Endosc 2019; 31: e74-e75

\section{Bibliography}

Endoscopy 2021; 53: E350-E351

DOI 10.1055/a-1290-7221

ISSN 0013-726X

published online 19.11 .2020

(c) 2020. Thieme. All rights reserved.

Georg Thieme Verlag KG, Rüdigerstraße 14,

70469 Stuttgart, Germany

\section{ENDOSCOPY E-VIDEOS \\ https://eref.thieme.de/e-videos}

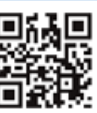

Endoscopy E-Videos is a free access online section, reporting on interesting cases and new

techniques in gastroenterological endoscopy. All papers include a high quality video and all contributions are freely accessible online.

This section has its own submission website at https://mc.manuscriptcentral.com/e-videos 